\title{
A Single-Point-Fed Wideband Circularly Polarized Rectangular Dielectric Resonator Antenna
}

\author{
Deqiang Yang, Meng Zou, and Jin Pan \\ Department of Microwave Engineering, School of Electronic Engineering, University of Electronic Science and \\ Technology of China (UESTC), Chengdu 611731, China
}

Correspondence should be addressed to Meng Zou; zm.1598@163.com

Received 18 October 2015; Revised 10 December 2015; Accepted 24 December 2015

Academic Editor: Ikmo Park

Copyright (C) 2016 Deqiang Yang et al. This is an open access article distributed under the Creative Commons Attribution License, which permits unrestricted use, distribution, and reproduction in any medium, provided the original work is properly cited.

A single-point-fed circularly polarized (CP) rectangular dielectric resonator antenna (DRA) with wide CP bandwidth is presented. By using $\mathrm{TE}_{111}$ and $\mathrm{TE}_{113}$ modes of the rectangular $\mathrm{DRA}$, a wideband $\mathrm{CP}$ performance is achieved. The coupling slot of the antenna contains a resistor loaded monofilar-spiral-slot and four linear slots. Design concept of the proposed antenna is demonstrated by simulations, and parameter studies are carried out. Prototype of the proposed antenna was fabricated and measured. Good agreement between the simulation and measurement is obtained. The measured impedance bandwidth $\left(\left|S_{11}\right|<-10 \mathrm{~dB}\right)$ and $3 \mathrm{~dB}$ axial-ratio (AR) bandwidth are $51.4 \%(1.91-3.23 \mathrm{GHz})$ and $33.0 \%(2.15-3.00 \mathrm{GHz})$, respectively.

\section{Introduction}

Dielectric resonator antenna (DRA) [1-4] is a good candidate for wireless service equipment due to its attractive characteristics such as small size, wide bandwidth, and high radiation efficiency.

DRAs with circular polarization (CP) performance are more applicable for the wireless systems than the linearly polarized (LP) ones [5-9], because the CP wireless systems can support flexible orientation between the receiving and transmitting antennas. The published CP DRAs can be divided into two classes: single-point-fed [5-7] and dualpoint-fed $[8,9]$ ones. Single-point-fed CP DRA is easy to implement, but its axial-ratio (AR) bandwidth is narrow. Dual-point-fed CP DRA has a wider AR bandwidth, but it needs a complicated power divider. Recently, several singlepoint-fed CP DRAs with wide $3 \mathrm{~dB}$ AR bandwidths have been reported. For example, a CP hollow rectangular DRA with wide AR bandwidth of $12.4 \%$ has been reported in [10]. In [11], simple inclined slot fed CP trapezoidal DRA with an AR bandwidth of as wide as $21.5 \%$ has been obtained. Single-point-fed wideband CP DRAs can also be realized by using novel feeding structures [12-14]. And in [15], a $3 \mathrm{~dB}$ AR bandwidth of $24.6 \%$ has been achieved by merging resonances of the DRA and coupling slot.
In recent years, some CP DRAs with wideband $[16,17]$ and dual-band $[18,19]$ performances have been realized by taking advantages of the higher order modes of the DRAs. In this letter, a single-point-fed wideband CP rectangular DRA using higher order mode is investigated. The $\mathrm{TE}_{111}$ and $\mathrm{TE}_{113}$ modes of rectangular DRA are excited by microstrip line through a slot etched on ground plane to achieve wideband CP operation. Ansoft HFSS [20] was used to simulate the performances of the proposed DRA. Parametric studies have also been carried out to investigate the DRA. To verify the simulation, a prototype antenna was fabricated and measured. Reasonable agreement between the simulated and measured results was attained. The measured results show a wide $3 \mathrm{~dB}$ AR bandwidth of $33.0 \%$ and a wide impedance bandwidth $\left(\left|S_{11}\right|<-10 \mathrm{~dB}\right)$ of $51.4 \%$.

\section{Antenna Structure}

Geometry of the single-point-fed wideband CP rectangular DRA is shown in Figure 1. The rectangular DRA has dimensions of $a=b=22 \mathrm{~mm}$ and $c=40 \mathrm{~mm}$, and it is manufactured from a ceramic material with permittivity of $\varepsilon_{r}=10$. The substrate $\left(\varepsilon_{r s}=2.2\right)$ has a side length of $l_{g}=50 \mathrm{~mm}$ and a thickness of $t=1 \mathrm{~mm}$. The coupling slot etched on the ground plane consists of a monofilar-spiral-slot and four linear slots. 


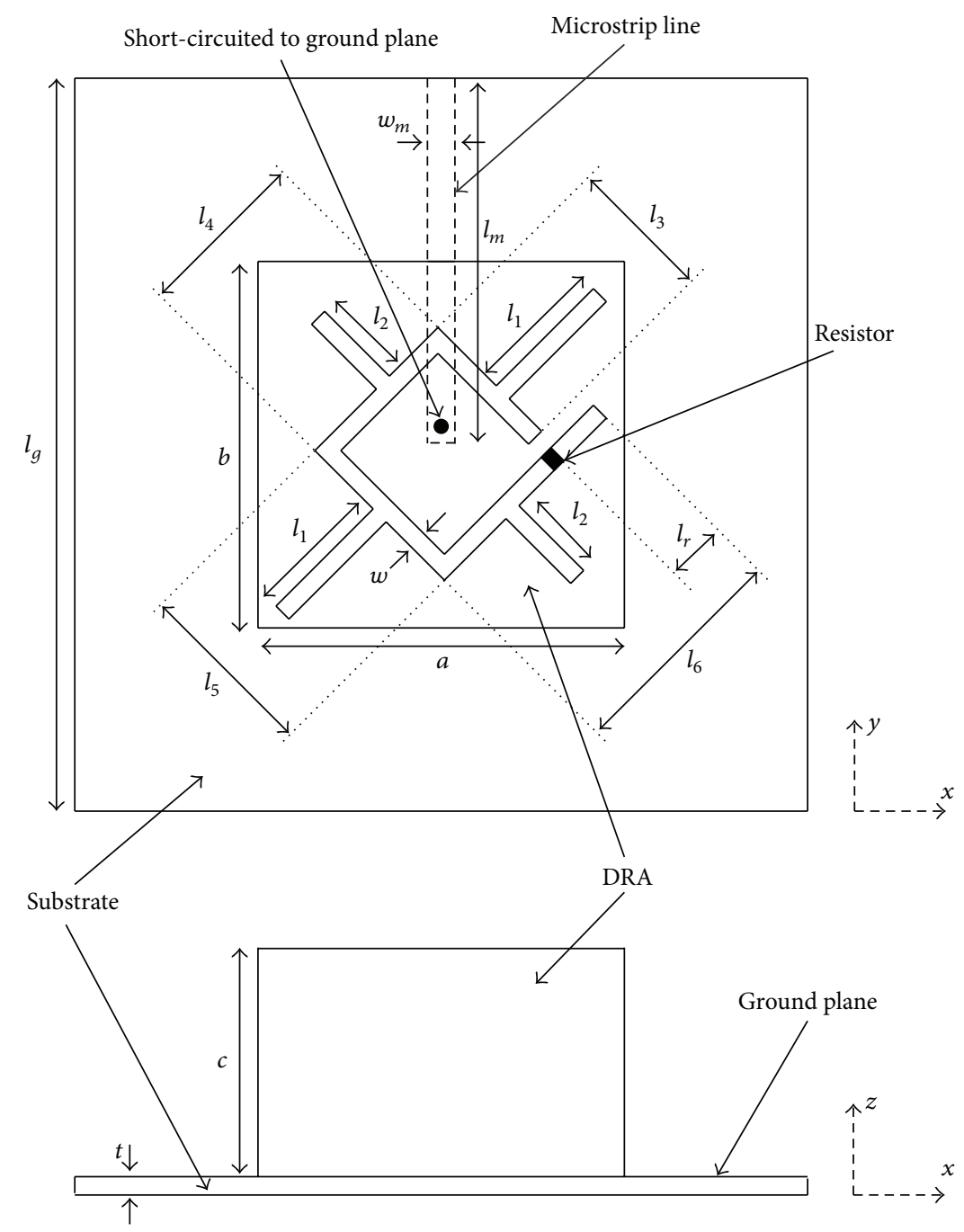

FIGURE 1: Geometry of the proposed single-point-fed wideband CP rectangular DRA.

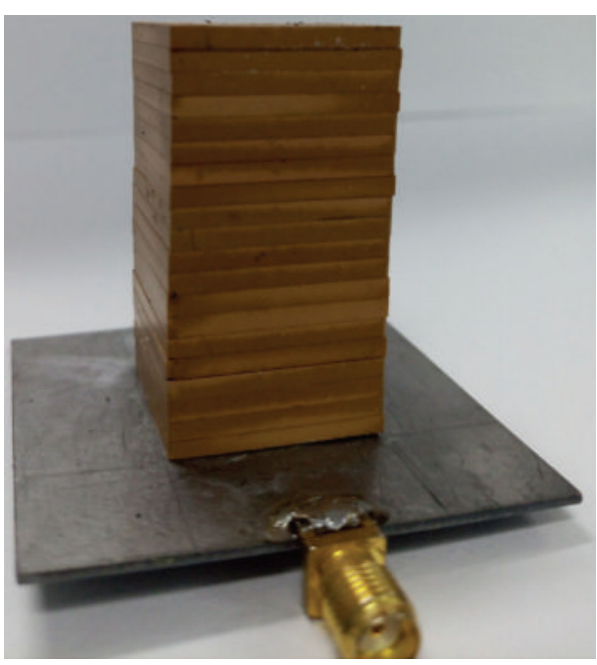

$3 \mathrm{D}$ view

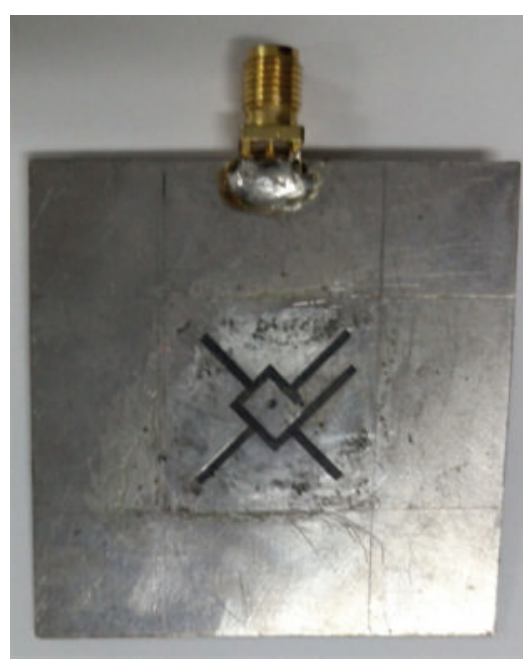

Coupling slot

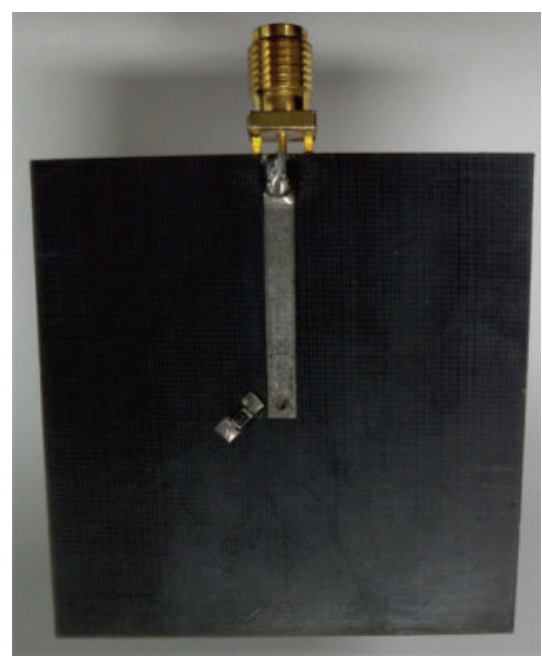

Bottom view

Figure 2: Photographs of the fabricated antenna. 


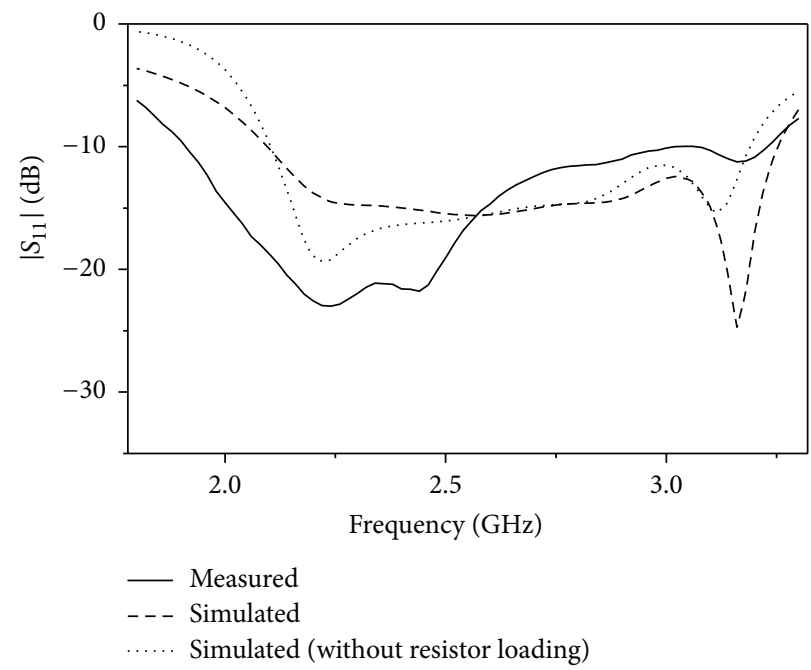

FIGURE 3: Simulated and measured reflection coefficients of the proposed single-point-fed wideband CP rectangular DRA.

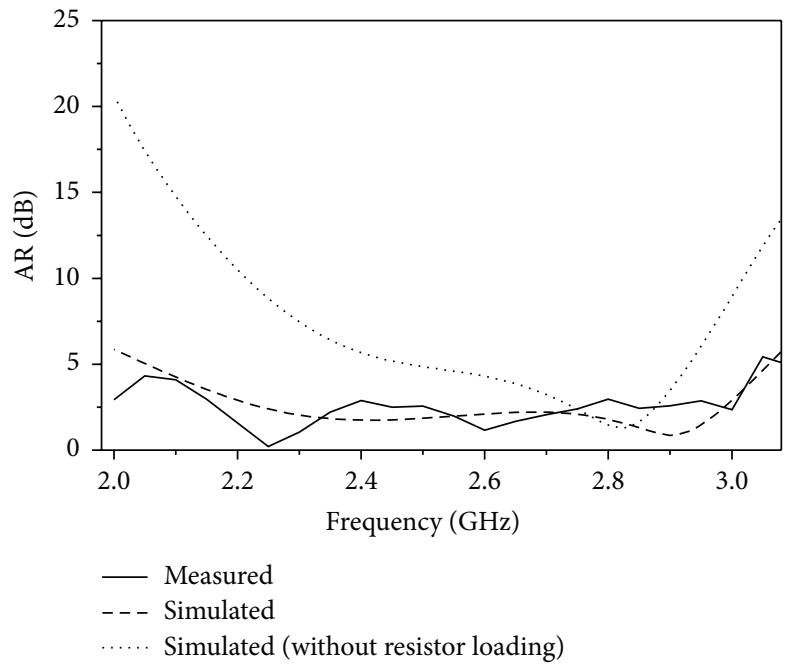

FIGURE 4: Simulated and measured axial ratios of the proposed single-point-fed wideband CP rectangular DRA.

The width of the slot is $w=1 \mathrm{~mm}$. Main side lengths of the monofilar-spiral-slot are $l_{3}=6 \mathrm{~mm}, l_{4}=6 \mathrm{~mm}, l_{5}=7 \mathrm{~mm}$, and $l_{6}=12 \mathrm{~mm}$. Lengths of the slot arms located at $45^{\circ}$ and $225^{\circ}$ with respect to the $x$-axis are equal to $l_{1}$. And the lengths of the other two slot arms located at $135^{\circ}$ and $315^{\circ}$ with respect to the $x$-axis are equal to $l_{2}$. For the proposed DRA, the lengths of linear slots are $l_{1}=8.0 \mathrm{~mm}$ and $l_{2}=6.8 \mathrm{~mm}$. A resistor with resistance of $R=62 \Omega$ is placed at $l_{r}=6 \mathrm{~mm}$ from the end of the slot. The $50 \Omega$ microstrip line $\left(w_{m}=3 \mathrm{~mm}, l_{m}=26 \mathrm{~mm}\right)$ is etched on the other side of substrate, and it is short-circuited to the ground plane at the end.

Resonant frequencies of $\mathrm{TE}_{111}$ and $\mathrm{TE}_{113}$ modes of the rectangular dielectric resonator (DR) can be calculated by using dielectric waveguide model (DWM) [21] or Ansoft HFSS. The calculated results of the DR in proposed antenna are shown in Table 1. Discrepancies between the two results are caused by error of the DWM.

\section{Results}

To verify the design, the proposed single-point-fed wideband CP rectangular DRA was fabricated and measured. Photographs of the fabricated antenna are shown in Figure 2. To avoid air gap between the DR and ground plane, the resistor is soldered at the bottom of the substrate by two via holes. Simulated and measured reflection coefficients of the proposed antenna are shown in Figure 3. Measured impedance bandwidth $\left(\left|S_{11}\right|<-10 \mathrm{~dB}\right)$ is $51.4 \%$ (1.91$3.23 \mathrm{GHz}$ ), and it agrees well with the simulated one. With reference to Figure 3, there are four resonant frequencies found at $2.24 \mathrm{GHz}, 2.44 \mathrm{GHz}, 2.84 \mathrm{GHz}$, and $3.16 \mathrm{GHz}$ across the measured impedance bandwidth. The first couple of resonant frequencies are due to the $\mathrm{TE}_{111}$ modes, and the second couple of resonant frequencies are caused by the $\mathrm{TE}_{113}$ modes. 

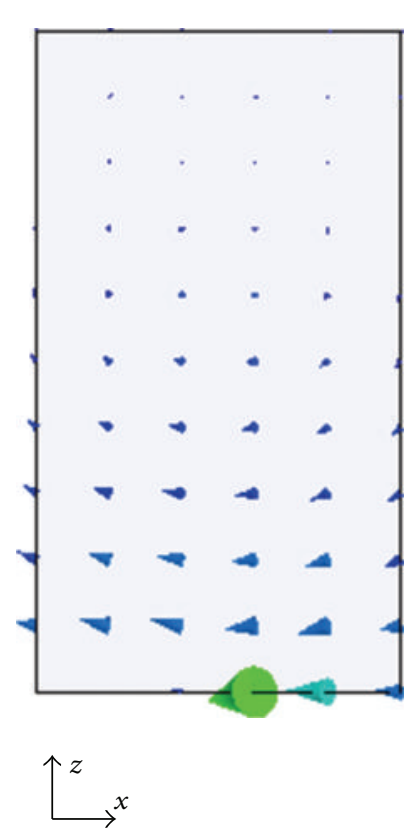

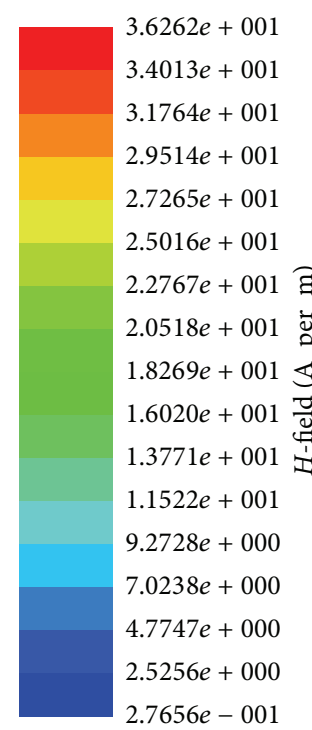

$2.7656 e-001$
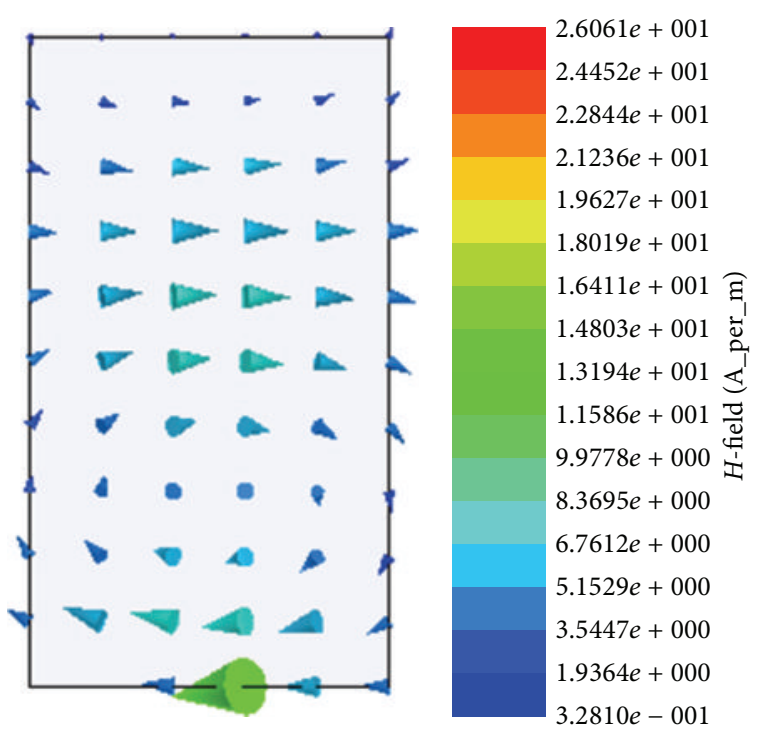

(a)

(b)

Figure 5: $H$-fields in the proposed single-point-fed wideband CP rectangular DRA. (a) $H$-fields at 2.42 GHz. (b) $H$-fields at $2.90 \mathrm{GHz}$.

TABLE 1: Calculated resonant frequencies of $\mathrm{TE}_{111}$ and $\mathrm{TE}_{113}$ modes of the proposed rectangular DR.

\begin{tabular}{lcc}
\hline Computing method & $\mathrm{TE}_{111}$ mode & $\mathrm{TE}_{113}$ mode \\
\hline DWM & $2.42 \mathrm{GHz}$ & $3.03 \mathrm{GHz}$ \\
Ansoft HFSS & $2.52 \mathrm{GHz}$ & $3.08 \mathrm{GHz}$ \\
\hline
\end{tabular}

Figure 4 shows the simulated and measured broadside ARs of the proposed antenna. The simulated and measured $3 \mathrm{~dB}$ AR bandwidth are $31.2 \%(2.19-3.00 \mathrm{GHz})$ and $33.0 \%$ $(2.15-3.00 \mathrm{GHz})$, respectively. From Figure 4, two simulated minimum AR values of $1.7 \mathrm{~dB}$ and $0.9 \mathrm{~dB}$ are obtained at $2.42 \mathrm{GHz}$ and $2.90 \mathrm{GHz}$, respectively. Simulated $H$-fields in the proposed DRA at $2.42 \mathrm{GHz}$ and $2.90 \mathrm{GHz}$ are shown in Figures 5(a) and 5(b). $\mathrm{H}$-field distributions demonstrate that the $\mathrm{TE}_{111}$ mode is excited at $2.42 \mathrm{GHz}$ and the $\mathrm{TE}_{113}$ mode is excited at $2.90 \mathrm{GHz}$. Figure 6 shows the simulated and measured patterns of the proposed single-point-fed wideband CP rectangular DRA. The radiation patterns of proposed antenna are broadside as expected, because both of the $\mathrm{TE}_{111}$ and $\mathrm{TE}_{113}$ are broadside modes. And the antenna is RHCP in broadside direction across the CP bandwidth. Figure 7 shows the simulated and measured RHCP gains of the proposed DRA. The measured peak RHCP gain is $6.8 \mathrm{dBi}$ at $2.70 \mathrm{GHz}$. And the measured result shows an average RHCP gain of $5.4 \mathrm{dBi}$ across the $3 \mathrm{~dB}$ AR bandwidth.

\section{Parametric Studies}

Effects of the resistor on antenna performances are investigated by HFSS simulations. Simulated AR of the proposed DRA without resistor loading is shown in Figure 4. The DRA without resistor has a $3 \mathrm{~dB}$ AR bandwidth of $6.1 \%$ (2.72$2.89 \mathrm{GHz}$ ). And the $3 \mathrm{~dB}$ AR bandwidth of the loaded one is about 5.0 times of the unloaded one. Simulated reflection coefficient of the unloaded one is shown in Figure 3. The resistor has a small effect on the reflection coefficient of the proposed antenna. Simulated total efficiencies of the proposed DRA with and without resistor loading are shown in Figure 8. The efficiency of the loaded one is smaller than the unloaded one because of the loss introduced by the resistor. The minimum efficiency and average efficiency of the loaded one across the CP bandwidth are 0.62 and 0.89 , respectively. Figure 9 shows the simulated RHCP and LHCP gains of the proposed DRA with and without resistor loading. From Figure 9, the LHCP component drops a lot when the antenna is loaded, and the resistor has a small effect on the RHCP component of the proposed antenna.

To explain the effect of resistor on antenna performance, the electric field $\vec{E}_{s}$ in the slot is studied. Figure 10 shows the simulated $\vec{E}_{s}$ at $f=2.4 \mathrm{GHz}$ and $f=2.9 \mathrm{GHz}$ in different time steps for the antenna without resistor loading. $\vec{E}_{s}$ is strong at the position of the resistor for $f=2.4 \mathrm{GHz}$, while it is weak at the position of the resistor for $f=2.9 \mathrm{GHz}$. This means that some power will be dissipated in the resistor at $2.4 \mathrm{GHz}$ and very little power will be lost in the resistor at $2.9 \mathrm{GHz}$ when the antenna is loaded, and that is why the resistor has effect on only lower band of the antenna. Moreover, it can be seen that the equivalent magnetic current $\left(\overrightarrow{M_{s}}=\overrightarrow{E_{s}} \times\right.$ $\widehat{Z}$ ) in the monofilar-spiral-slot at $2.4 \mathrm{GHz}$ is in a travelling waveform. The resistor, which acts as a resistive termination for the monofilar-spiral-slot, can improve travelling wave performance of the equivalent magnetic current and thus the $\mathrm{CP}$ performance at the lower band. 

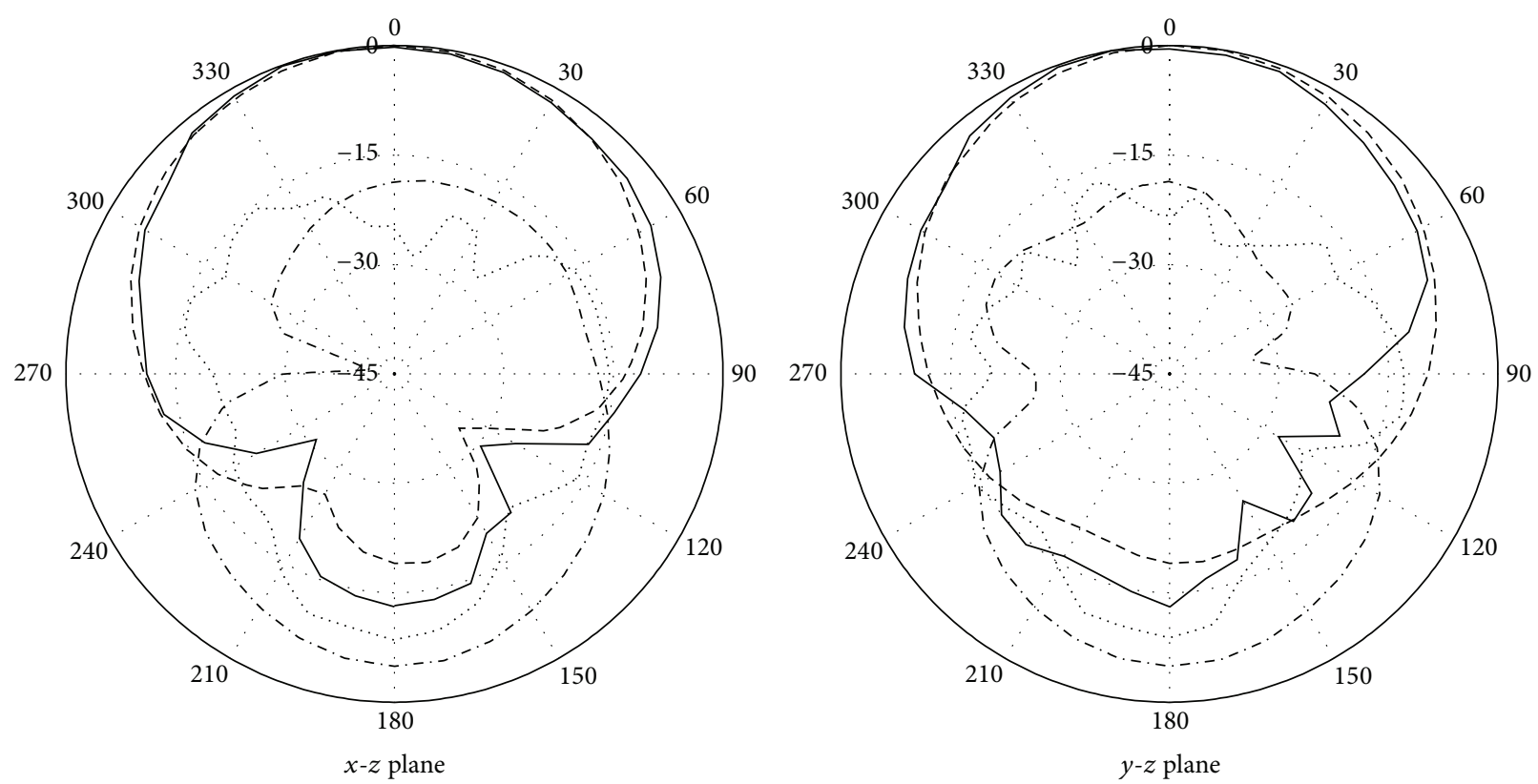

(a)
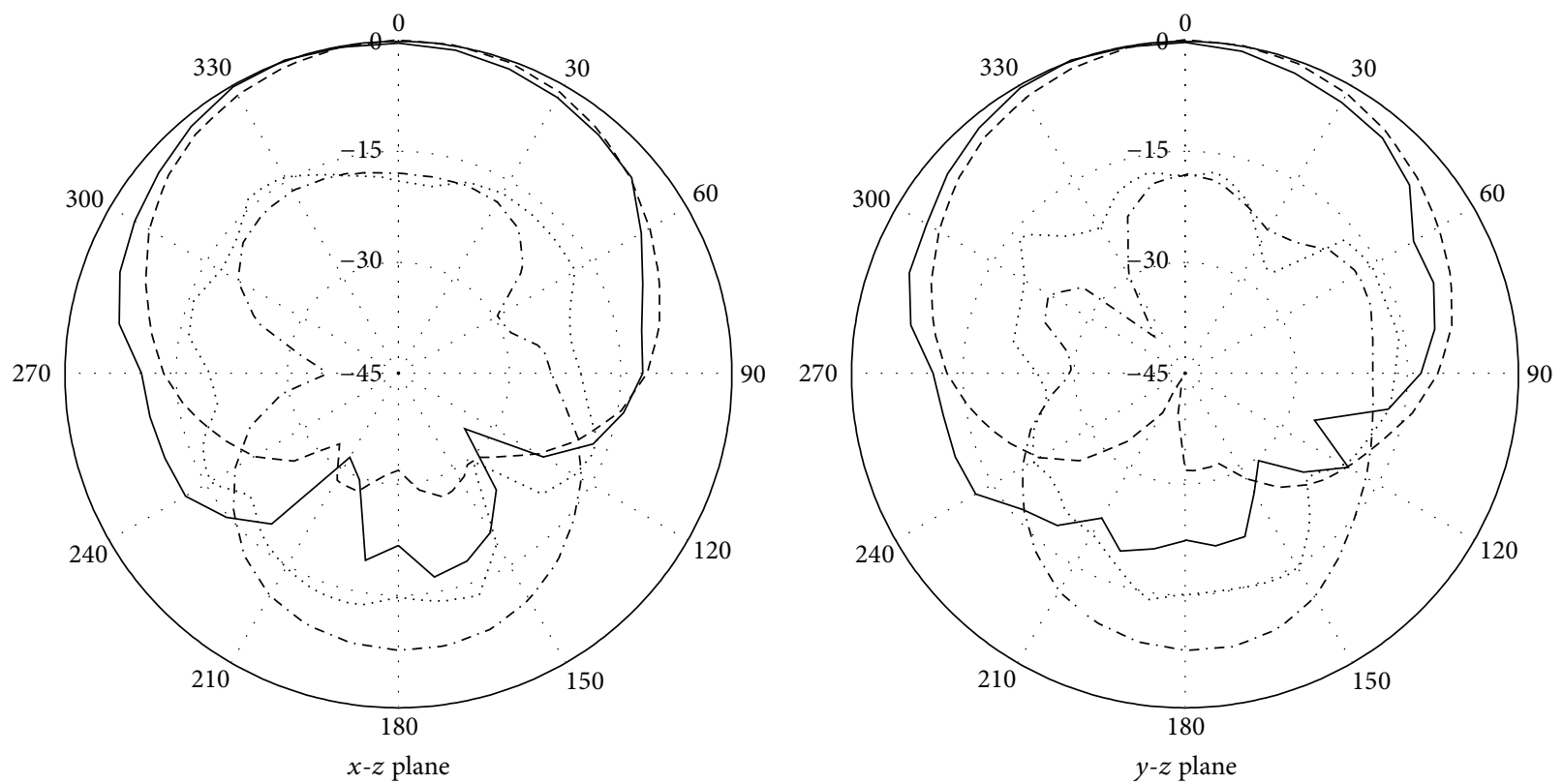

(b)

FIGURE 6: Simulated and measured radiation patterns of the proposed single-point-fed wideband CP rectangular DRA. (a) 2.3 GHz. (b) $2.7 \mathrm{GHz}$.

The AR and total efficiency for different values of $R$ are shown in Figure 11. With reference to the figure, the widest CP bandwidth is obtained at $R=60 \Omega$. And the total efficiency remains almost unchanged when $R$ increases from $20 \Omega$ to $100 \Omega$.

Effects of the location of resistor on antenna performances have also been studied. The $3 \mathrm{~dB}$ AR bandwidth as function of $l_{r}$ is shown in Figure 12, and it can be observed that CP bandwidth of the proposed antenna increases with the increase of $l_{r}$. Minimum total efficiency and average total efficiency across the $3 \mathrm{~dB}$ AR bandwidth versus $l_{r}$ are also exhibited in Figure 12. From Figure 12, both of the minimum and average total efficiency decrease with the increase of $l_{r}$. Proper value of $l_{r}$ can be decided based on Figure 12 and the special design objectives.

Comparison between the proposed antenna and some of the recently published single-point-fed CP DRAs is listed in Table 2. It is seen that the proposed antenna has a wide bandwidth and reasonable antenna efficiency. 


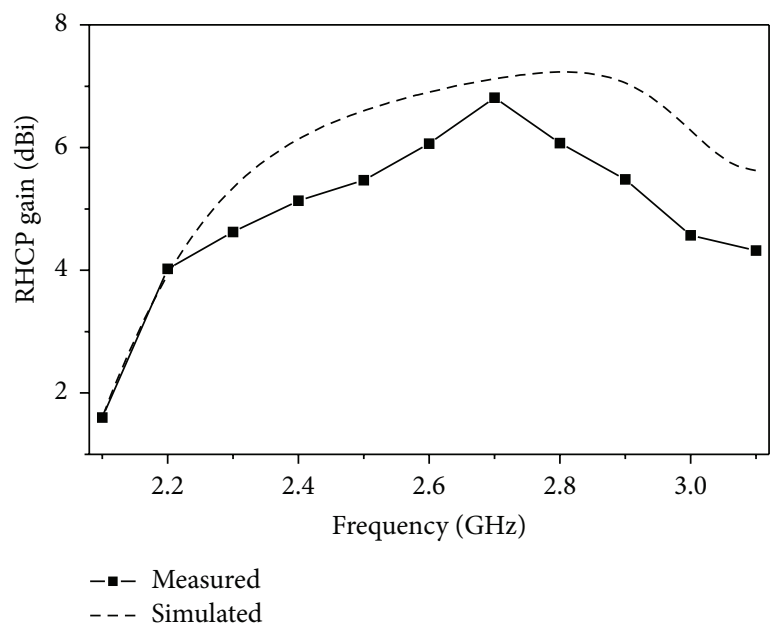

FIGURE 7: Simulated and measured RHCP gains of the proposed single-point-fed wideband CP rectangular DRA.

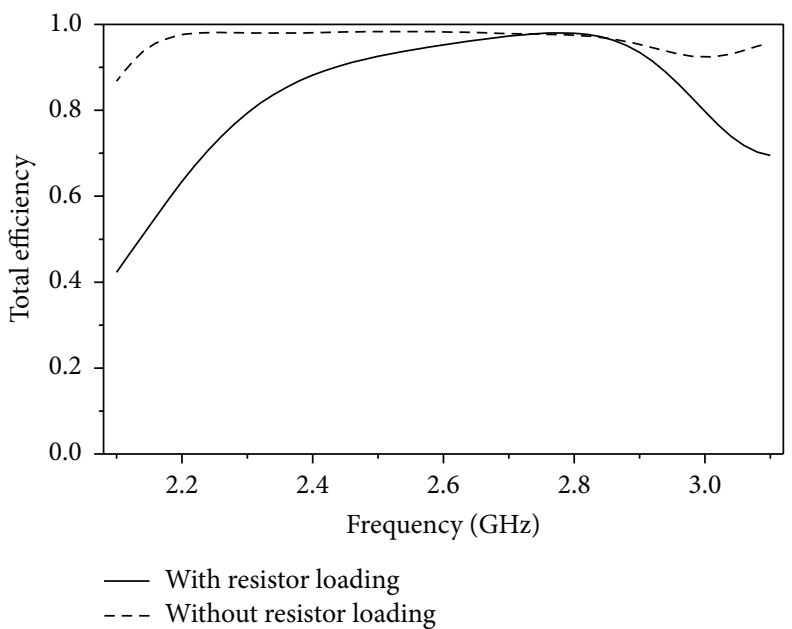

FIGURE 8: Simulated total efficiencies of the proposed DRA with and without resistor loading.

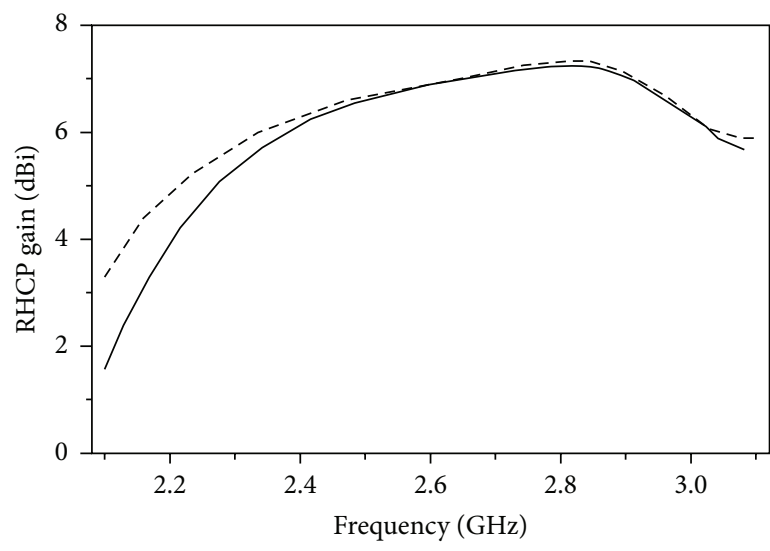

With resistor loading - - - Without resistor loading

(a)

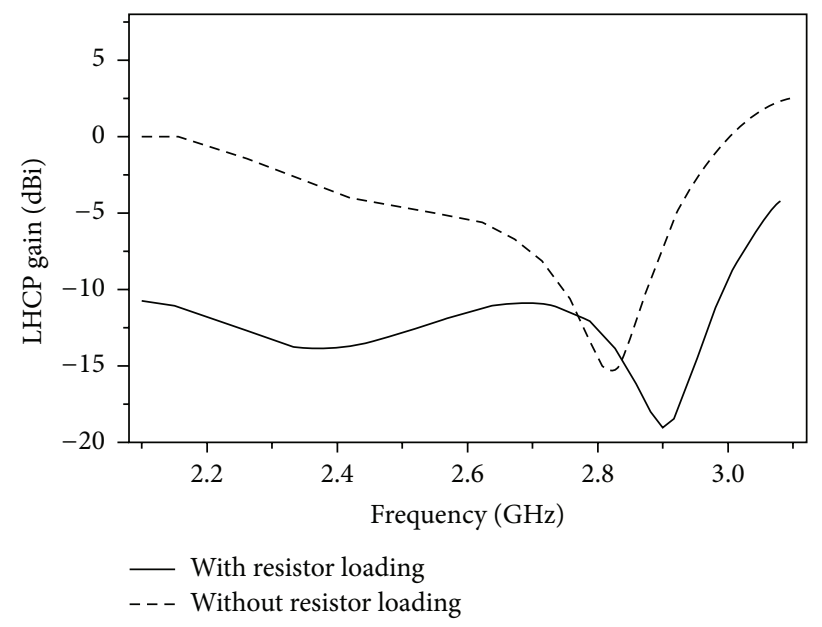

(b)

FIGURE 9: Simulated gains of the proposed DRA with and without resistor loading. (a) RHCP gains. (b) LHCP gains. 

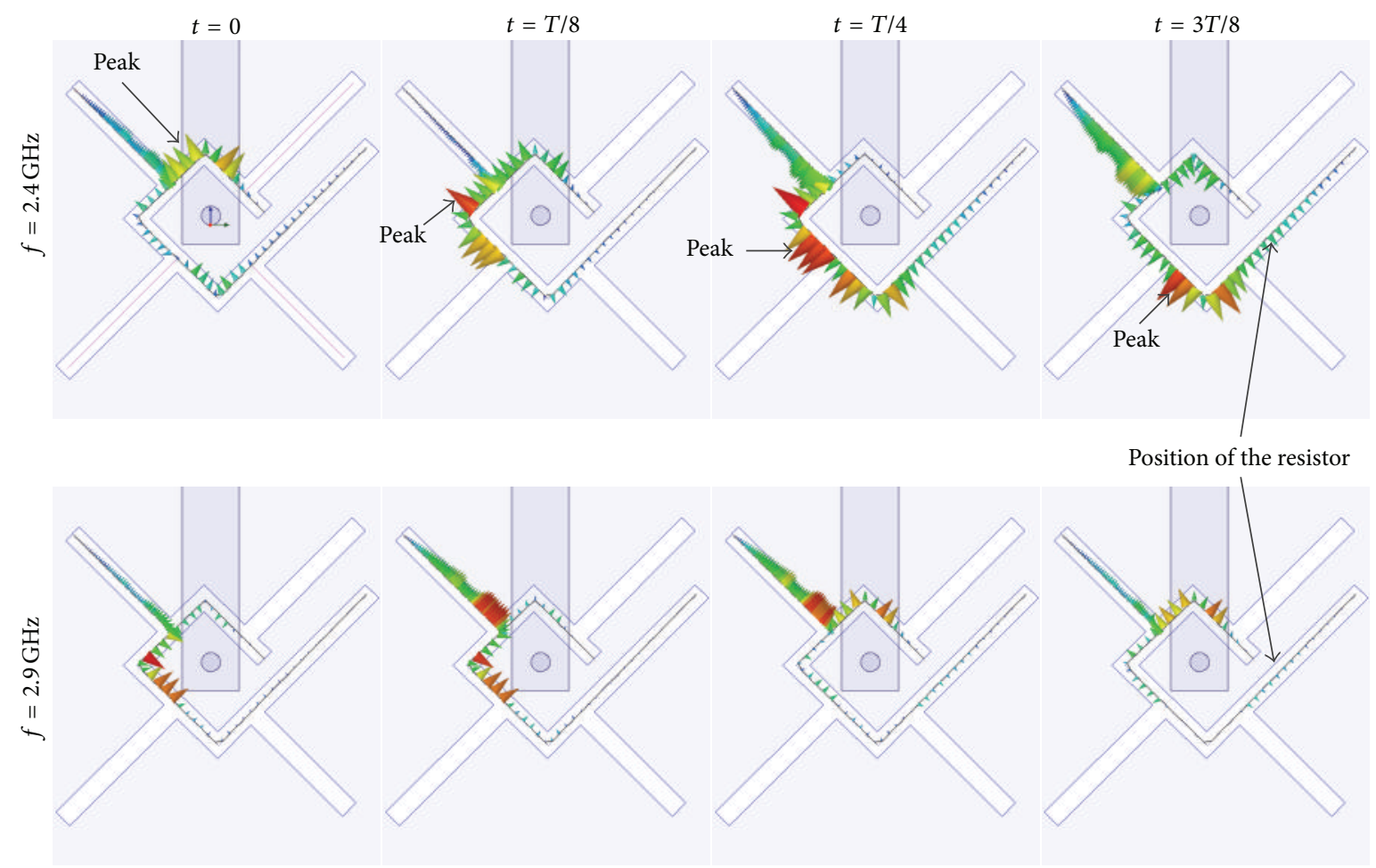

Figure 10: Simulated $\vec{E}_{s}$ in the slot. $(T=1 / f)$.

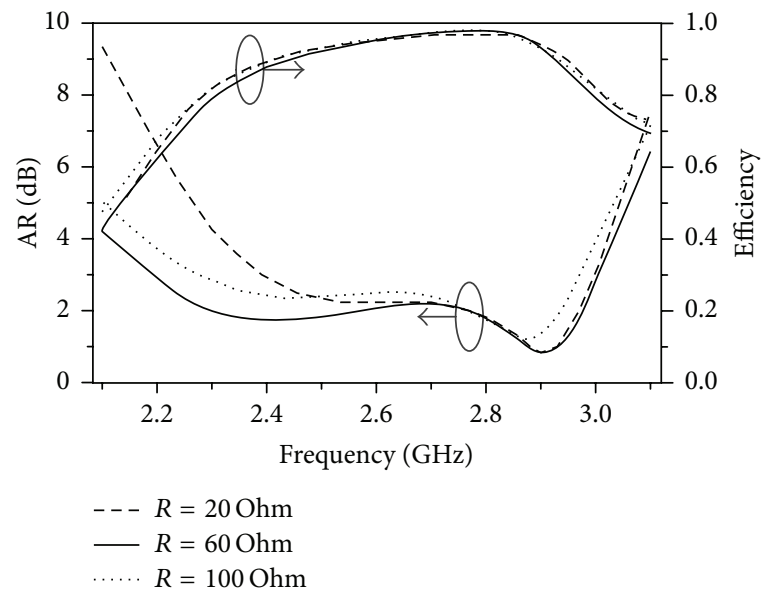

FIgURE 11: AR and total efficiency and for different values of $R$.

TABLE 2: Comparison between the proposed antenna and other published single-point-fed CP DRAs.

\begin{tabular}{|c|c|c|c|c|c|}
\hline DRA shape & $\varepsilon_{r}$ & $3 \mathrm{~dB}$ AR bandwidth & Impedance bandwidth & Average total efficiency & Reference \\
\hline Hollow rectangular & 9.4 & $12.4 \%$ & $32.5 \%$ & - & {$[10]$} \\
\hline Trapezoidal & 9.4 & $21.5 \%$ & $33.5 \%$ & $90 \%$ & [11] \\
\hline Rectangular & 9.2 & $14.0 \%$ & $19.0 \%$ & $98 \%$ & [12] \\
\hline Rectangular & 12 & $18.7 \%$ & $53.5 \%$ & $75 \%$ & {$[13]$} \\
\hline Rectangular & 12 & $25.5 \%$ & - & $82 \%$ & {$[14]$} \\
\hline Rectangular & 10 & $33.0 \%$ & $51.4 \%$ & $89 \%$ & Proposed \\
\hline
\end{tabular}




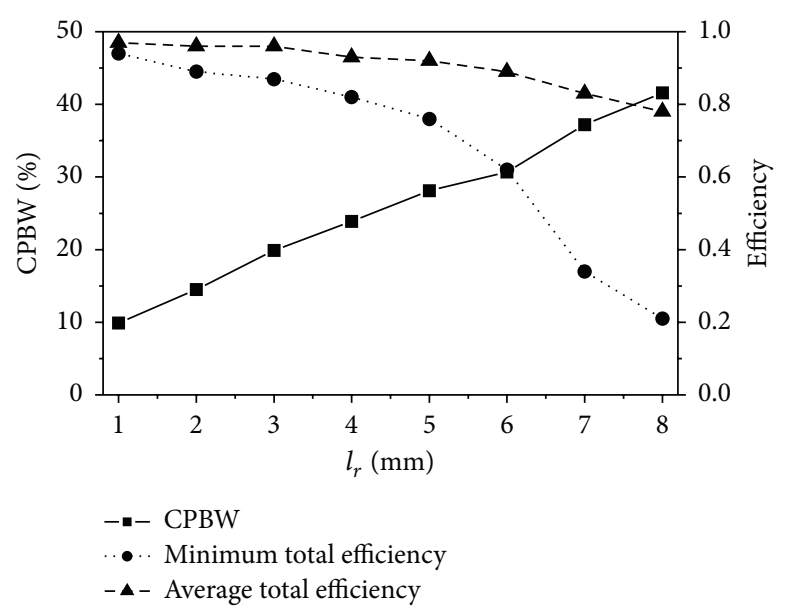

FIGURE 12: Effects of $l_{r}$ on AR and total efficiency of the proposed antenna.

\section{Conclusion}

A single-point-fed wideband CP rectangular DRA has been proposed and discussed in this letter. The design concept is based on utilizing the fundamental $\mathrm{TE}_{111}$ and high order $\mathrm{TE}_{113}$ modes of rectangular DRA. Proposed design concept has been certified by HFSS simulation. And parametric studies have been carried out to investigate effects of the resistor on antenna performances. A prototype antenna was designed and fabricated. The measured $3 \mathrm{~dB}$ AR bandwidth and impedance bandwidth $\left(\left|S_{11}\right|<-10 \mathrm{~dB}\right)$ are as wide as $33.0 \%$ and $51.4 \%$, respectively.

\section{Conflict of Interests}

The authors declare that there is no conflict of interests regarding the publication of this paper.

\section{References}

[1] S. A. Long, M. W. McAllister, and L. C. Shen, "The resonant cylindrical dielectric cavity antenna," IEEE Transactions on Antennas and Propagation, vol. 31, no. 3, pp. 406-412, 1983.

[2] K. M. Luk and K. W. Leung, Dielectric Resonator Antennas, Research Studies Press, Baldock, UK, 2003.

[3] K. W. Leung, E. H. Lim, and X. S. Fang, "Dielectric resonator antennas: from the basic to the aesthetic," Proceedings of the IEEE, vol. 100, no. 7, pp. 2181-2193, 2012.

[4] R. K. Mongia and A. Ittipiboon, "Theoretical and experimental investigations on rectangular dielectric resonator antennas," IEEE Transactions on Antennas and Propagation, vol. 45, no. 9, pp. 1348-1356, 1997.

[5] C.-Y. Huang, J. Y. Wu, and K. L. Wong, "Cross-slot-coupled microstrip antenna and dielectric resonator antenna for circular polarization," IEEE Transactions on Antennas and Propagation, vol. 47, no. 4, pp. 605-609, 1999.

[6] K. W. Leung and H. K. Ng, "Theory and experiment of circularly polarized dielectric resonator antenna with a parasitic patch," IEEE Transactions on Antennas and Propagation, vol. 51, no. 3, pp. 405-412, 2003.
[7] G. Almpanis, C. Fumeaux, and R. Vahldieck, "Offset cross-slotcoupled dielectric resonator antenna for circular polarization," IEEE Microwave and Wireless Components Letters, vol. 16, no. 8, pp. 461-463, 2006.

[8] K. W. Leung, W. C. Wong, K. M. Luk, and E. K. N. Yung, "Circular-polarised dielectric resonator antenna excited by dual conformal strips," Electronics Letters, vol. 36, no. 6, pp. 484-486, 2000.

[9] R.-C. Han, S.-S. Zhong, and J. Liu, "Broadband circularly polarised dielectric resonator antenna fed by wideband switched line coupler," Electronics Letters, vol. 50, no. 10, pp. 725-726, 2014.

[10] K. Lu, K. W. Leung, and Y. M. Pan, "Theory and experiment of the hollow rectangular dielectric resonator antenna," IEEE Antennas and Wireless Propagation Letters, vol. 10, pp. 631-634, 2011.

[11] Y. Pan and K. W. Leung, "Wideband circularly polarized trapezoidal dielectric resonator antenna," IEEE Antennas and Wireless Propagation Letters, vol. 9, pp. 588-591, 2010.

[12] M. I. Sulaiman and S. K. Khamas, "A singly fed wideband circularly polarized dielectric resonator antenna using concentric open half-loops," IEEE Antennas and Wireless Propagation Letters, vol. 10, pp. 1305-1308, 2011.

[13] M. Zou, J. Pan, Z. Nie, and P. Li, "A wideband circularly polarized rectangular dielectric resonator antenna excited by a lumped resistively loaded monofilar-spiral-slot," IEEE Antennas and Wireless Propagation Letters, vol. 12, pp. 1646-1649, 2013.

[14] M. Zou, J. Pan, and Z. Nie, "A wideband circularly polarized rectangular dielectric resonator antenna excited by an archimedean spiral slot," IEEE Antennas and Wireless Propagation Letters, vol. 14, pp. 446-449, 2015.

[15] M. Zou and J. Pan, "Wideband hybrid circularly polarised rectangular dielectric resonator antenna excited by modified cross-slot," Electronics Letters, vol. 50, no. 16, pp. 1123-1125, 2014.

[16] B. Li, C.-X. Hao, and X.-Q. Sheng, "A dual-mode quadraturefed wideband circularly polarized dielectric resonator antenna," IEEE Antennas and Wireless Propagation Letters, vol. 8, pp. 1036-1038, 2009.

[17] X. S. Fang and K. W. Leung, "Linear-/circular-polarization designs of dual-/wide-band cylindrical dielectric resonator antennas," IEEE Transactions on Antennas and Propagation, vol. 60, no. 6, pp. 2662-2671, 2012. 
[18] M. Zhang, B. Li, and X. Lv, "Cross-slot-coupled wide dual-band circularly polarized rectangular dielectric resonator antenna," IEEE Antennas and Wireless Propagation Letters, vol. 13, pp. 532535, 2014.

[19] X. Fang, K. W. Leung, and E. H. Lim, "Singly-fed dualband circularly polarized dielectric resonator antenna," IEEE Antennas and Wireless Propagation Letters, vol. 13, pp. 995-998, 2014.

[20] Ansoft high frequency structure simulator (HFSS), ver. 12.0, Ansoft corp, 2009.

[21] R. K. Mongia, "Theoretical and experimental resonant frequencies of rectangular dielectric resonators," IEE Proceedings Microwaves, Antennas and Propagation, vol. 139, no. 1, pp. 98104, 1992. 


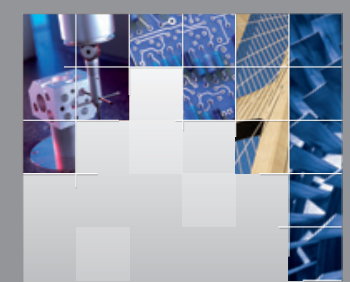

\section{Enfincering}
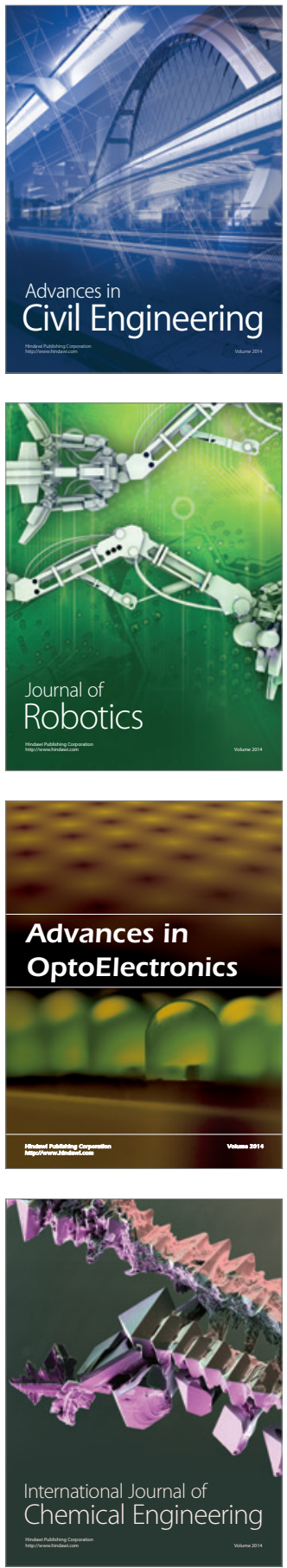

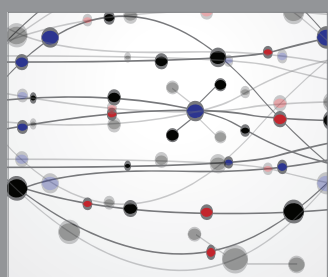

The Scientific World Journal

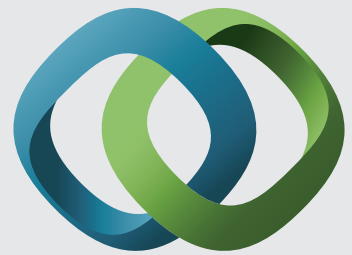

\section{Hindawi}

Submit your manuscripts at

http://www.hindawi.com
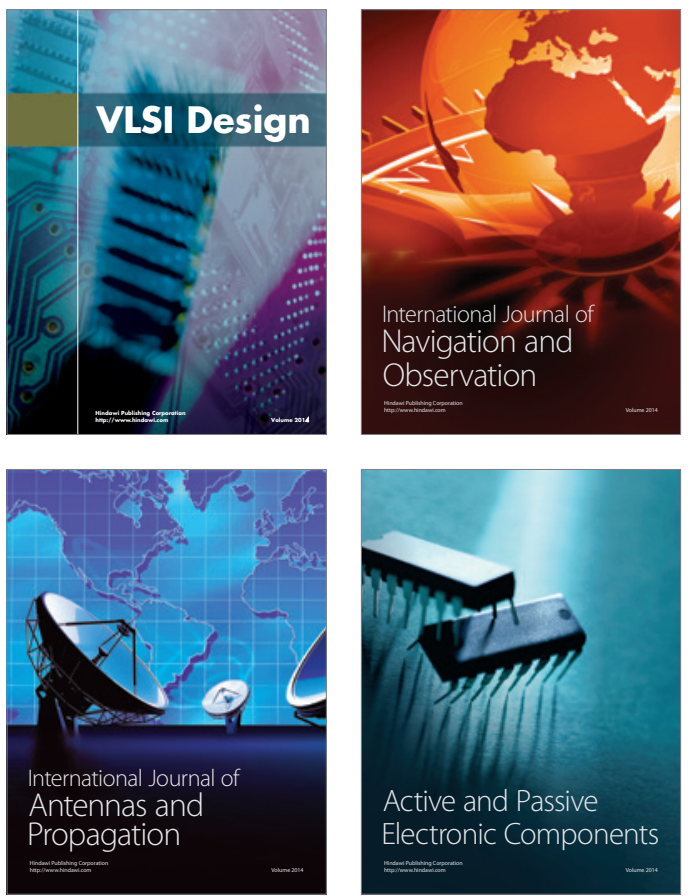
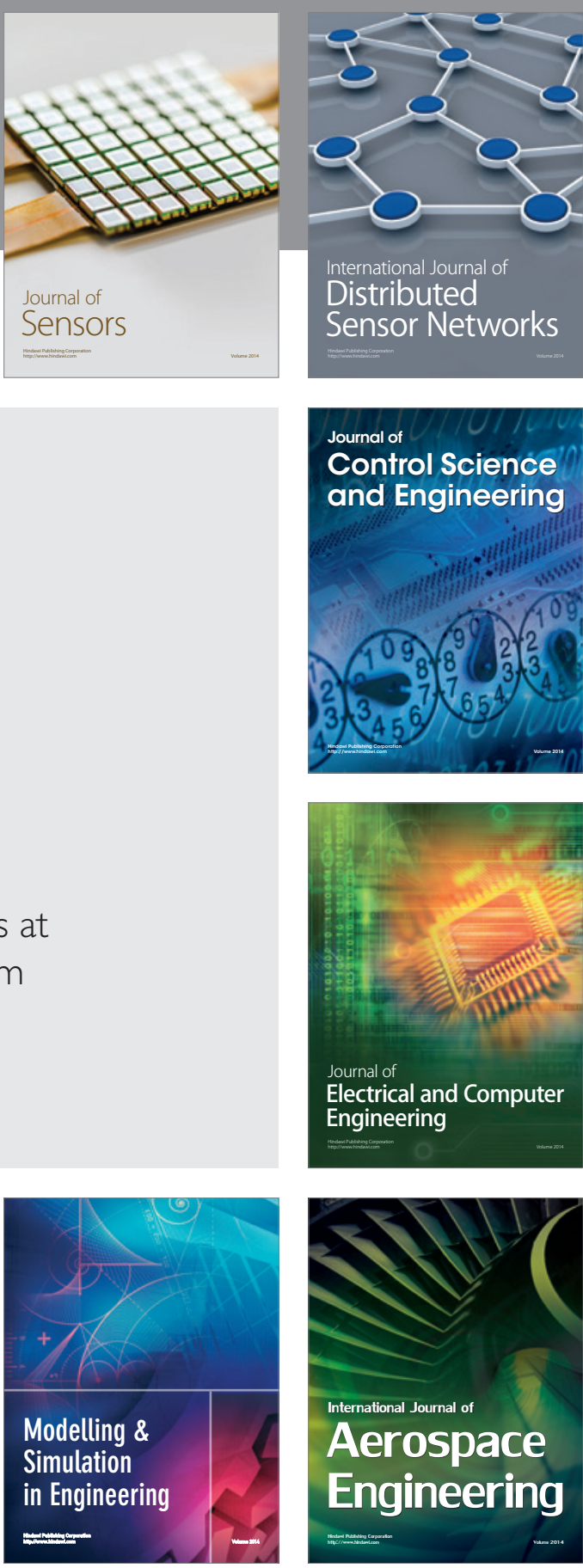

International Journal of

Distributed

Sensor Networks

Journal of

Control Science

and Engineering
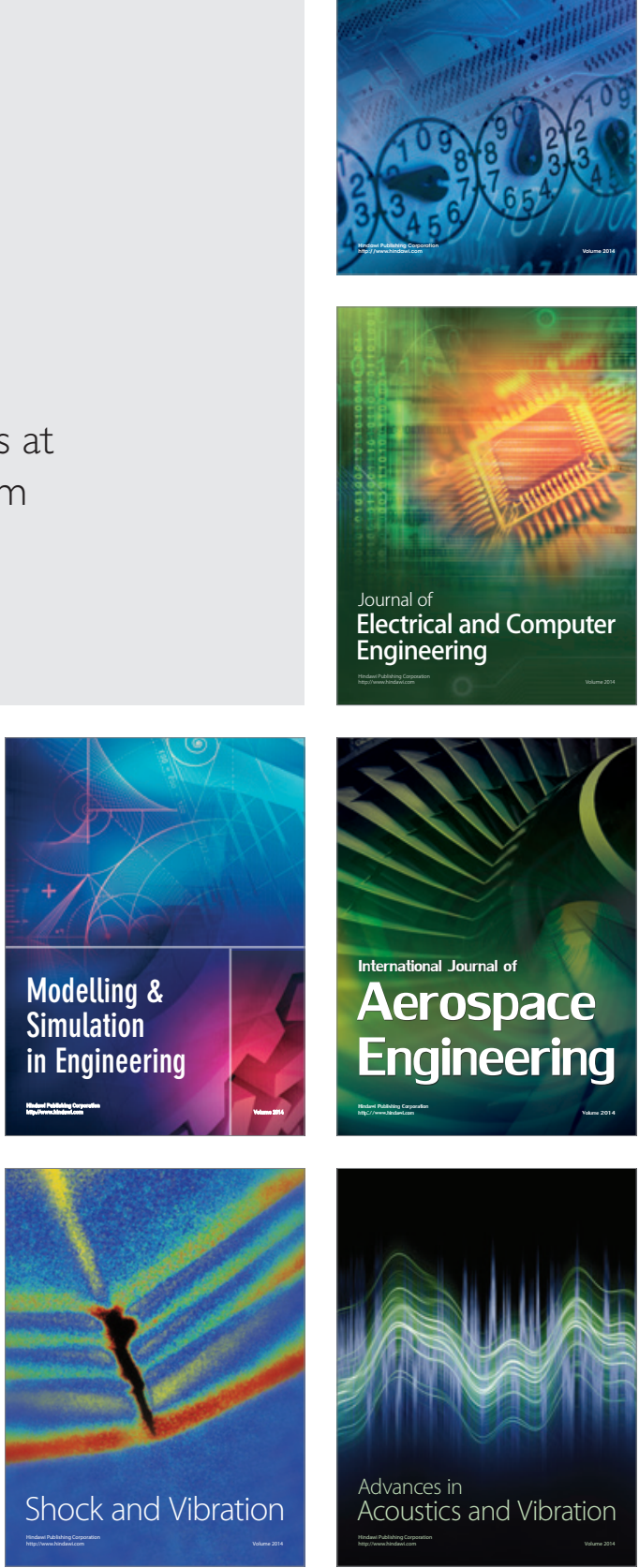